\title{
Urban Systems Design: A Conceptual Framework for Planning Smart Communities
}

\author{
Michael B. Tobey ${ }^{1,2}$, Robert B. Binder ${ }^{1,3}$, Soowon Chang ${ }^{1,4}$, Takahiro Yoshida ${ }^{1}{ }^{(0)}$, \\ Yoshiki Yamagata $1, * \mathbb{C}$ and Perry P. J. Yang ${ }^{4}$ \\ 1 Center for Global Environmental Research, National Institute for Environmental Studies, Tsukuba, \\ Ibaraki 305-8506, Japan; mbtobey@uw.edu (M.B.T.); rbinder@usc.edu (R.B.B.); soowonch@gatech.edu (S.C.); \\ yoshida.takahiro@nies.go.jp (T.Y.) \\ 2 College of Built Environments, University of Washington, Seattle, WA 98195, USA \\ 3 Sol Price School of Public Policy, University of Southern California, Los Angeles, CA 90007, USA \\ 4 Eco Urban Lab, College of Design, Georgia Institute of Technology, Atlanta, GA 30332, USA; \\ perry.yang@design.gatech.edu \\ * Correspondence: yamagata@nies.go.jp
}

Received: 30 August 2019; Accepted: 23 October 2019; Published: 19 November 2019

\begin{abstract}
Urban systems design arises from disparate current planning approaches (urban design, Planning Support Systems, and community engagement), compounded by the reemergence of rational planning methods from new technology (Internet of Things (IoT), metric based analysis, and big data). The proposed methods join social considerations (Human Well-Being), environmental needs (Sustainability), climate change and disaster mitigation (Resilience), and prosperity (Economics) as the four foundational pillars. Urban systems design integrates planning methodologies to systematically tackle urban challenges, using IoT and rational methods, while human beings form the core of all analysis and objectives. Our approach utilizes an iterative three-phase development loop to contextualize, evaluate, plan and design scenarios for the specific needs of communities. An equal emphasis is placed on feedback loops through analysis and design, to achieve the end goal of building smart communities.
\end{abstract}

Keywords: urban design; Planning Support System; resilience; sustainability; economics; human factors; big data

\section{Introduction}

Modern planning, as a unified practice of coherent theory, is an invention of the late 19th to early 20 th century which arose to meet the growing challenges and complexities of urbanity. Settlement forms and organic growth patterns were unable to keep pace with the increasing complexities of urbanization from the local to global levels. The planning profession's early theoretical iteration, rational planning, attempted to mitigate and solve these problems through the application of the scientific method and statistical modeling [1]. However, contemporaries such as Patsy Healey and Paul Davidoff noted in their work the failings of these methods for ignoring the social factors and the unmeasurable nature of these interactions [2,3]. Social, communicative, and advocacy planning were theorized as direct counters to rational planning, aligning professional aims to empowerment and societal effects. However, smart cities and their associated technologies seek to revive and refine these older, static rational modeling approaches in new contexts for the purpose of designing future cities which better serve humanity and the environment.

Urban systems design (USD) seeks to blend the beneficial elements of systems thinking, rationalism and metric-based analysis, while tempering them, and to focus on the social interactions and design 
interventions that drive cities. Building upon the traditions and collective knowledge of the planning profession and the existing three pillars of sustainability, outlined by the World Commission in 1987, the proposed framework seeks to design smart communities balanced on four pillars: Resilience, Economics, Sustainability, and Human Well-Being [4]. Humans are the fundamental element from which cities are constructed. Their environment is enacted and changed by their interactions. It is essential to consider complex relations and nexus of human and environmental needs, given their foundational qualities in their continued existence.

The paper seeks to outline a conceptual framework planning smart communities based on the practice of urban systems design. Accomplishing this task requires expounding core principles upon which this approach is developed: historic practices, the controversies associated with data, their applications, and system complexity behind. This USD method is built upon three phases: contextualization, evaluation, and iterative change that are further explored in this paper.

\section{Background}

Historical cities were planned from an initial event and then allowed to grow organically, within examples such as Chinese traditions, Roman, etc. [5]. Modern city planning, however, found its primacy in the industrial cities of Europe and the North America when cities were continuously planned, regulated, and iterated through design. In this period, the Garden City Movement was one of the attempts to mitigate the harmful effects of industrialization, while extolling the virtues and morality of nature and organic systems, by employing rationalization as the basis of design-as proposed by E. Howard in 1902 [6]. Rationalism became rooted in the field with the idea that with metrics, new technologies, and the great innovative minds of the early 20th century, the problems of the cities would be solved [1]. The well-known group of New York City intellectuals that became known as the Regional Planning Association of America (RPAA) planned and implemented ideas that were grounded in rationalism, in particular highlighted in Lewis Mumford's book, The Story of Utopia, and Clarence Stein's Sunnyside Homes and Radburn developments [7]. There was some success from the group's rational methods, like the Appalachian Trail. However, rational planning was largely grounded in theory without the backing of research and practice. The destruction of communities, capital, and social cohesion-following the implementation of many of the early ideals that grew from rational planning theory within transportation planning practices, suburbanization and housing practices [7] - and the discrediting of social factors [8], are examples of why rational planning in its early form created problematic outcomes. These modernist movements were rejected as contemporary planning diverged into a myriad of thoughts and theories pertaining to the planning profession.

From this turbulent time emerged the general categories of contemporary theories which permeate planning discourse, such as resilient design, human-centric design and community-driven design and landscape urbanism approaches. In Eraydin's article "'Resilience Thinking' for planning" [9], resilient communities and design revolve around more than physical systems (flood protection, adaptive strategies, etc.) and must include social systems (community connections, neighborhood trust, etc.) which together can aid in adapting to climatic change. Resilience speaks to adaptability of social and physical systems to handle and respond to structural and environmental pressures [10]. Where resilience focuses on the ability of a system to adapt to changes, sustainability examines the longevity and long-term effects of a system. The core concern is to prevent the exploitation of the present at the expense of the future. Human-centered design and community-driven design approaches are intrinsically motivated by the human experience, as either individuals or in aggregate. Human-centered design, lauded by Mike Cooley, is an approach to interactive systems development that aims to make systems usable and useful by focusing on the users, their needs and requirements, and by applying human factors/ergonomics, usability knowledge, and techniques [11]. Community-driven design, influenced by Paul Davidoff's advocacy model of intervention, tends to be a more macroscopic approach to aggregation and interventions, focusing on empowerment and the collective needs of individuals in communities [12]. Landscape urbanism took a proposition that landscape can be seen as an essential 
block for organizing cities and the urban environment. Grounded on landscape ecology, it emphasizes not only patterns and forms of the environment, but also its flows and ecological functions behind, as well as its temporal processes and changes.

The recent proposition in smart cities brings in a new dimension that contains potential links to the ideas of rationalism, in which the reliance of data, analytics and statistical modeling would facilitate the creation of better city plans. Several elements are core to the premise: information and communication technologies, sustainable development, citizen engagement, government system integration, new modes of transportation, Internet of Things (IoT) and their integration [13].

Each of these design approaches, despite divergent aims, are constructed on the same framework of problem identification and examination. Modern city planning fails to adequately capture the connected and complex nexus of system interactions involved in making decisions [14-16]. Synthesizing these theories through the careful application of data, systematic approaches, and community integration using consistent metrics will lead to better and more understandable plans. Data, informatics, and rational methods are again resurgent in the field and discourse of planning. This resurgence has been brought on by an emphasis on the need to update planning methodologies according to emerging technologies and increasing computational capacities (e.g., IoT, big data, etc.). The collective theories of Michael Batty and Juval Portugali, among others, expose the necessity of these theories to address the betterment of the human conditions $[15,17,18]$. Sensing technology, the omnipresence of computing technology, and the availability of many types of personal data would require novel planning methods to handle urban issues of our time. One of which is the care to which data collection and application is applied given the ability to perpetuate existing errors forward or discount non-quantifiable metrics.

These issues are pertaining to disruptive technologies that are often connected with smart cities. Applications of these technologies, autonomous vehicles (AVs) as an example, potentially perpetuate the same sets of challenges to current planning methods as older ones but with a new gimmick - new means with old methods reproducing old failures anew. The manner in which these methods and new technologies are considered, discussed, or evidenced (a storyline), and by who these complex set of systems are crafted, can greatly impact their outcomes [19], functionality, and the diffusion of services [20]. Involvement in these new methods must then include the social subsystem at work in urban environments as a systematic vision-one that has to account for urban agents in a complex dynamic manner with spatial system consequences from various agents both local (residents) and foreign (visitors) [21]. One potential way of meeting the challenges of converging demands and designing within complex systems is treating neighborhoods as the principle unit of design, study, and basis for these systems. Al-Thani, Skelhorn, Amato, Koc, and Al-Ghamdi argue that sustainable urbanism, for smart cities and technologies, can be best achieved through the use of mixed-used and polycentric neighborhoods and cities with technology acting as a support, but not as the governing component [22]. However, this approach still lacks a finer grain approach and connection below the neighborhood in reflecting the parts and designs which create it.

Urban systems design deals with a series of nested complex systems-where the nexus of system interactions can be studied and evaluated. They is a system of systems that all interact and engage with each other in an inclusive or mutually exclusive system tree. As such, the effects on one system will influence another or result in the inability to positively affect it. System complexity is defined as dynamic, unpredictable and multi-dimensional-consisting of a collection of interconnected relationships and parts. Unlike "cause and effect" or linear thinking, complexity is characterized by non-linearity [23], as urban systems are a set of complex systems with multiple actors and decision processes occurring internally to themselves and with adjacent systems. Careful consideration must be given to deciding which systems to include, to ignore, or to further simplify.

The concept of a holon fits as a framing device for understanding and linking these independent and interdependent systems. Holons are a way of conceptualizing complex systems that are simultaneously a part of and a whole in a larger system where their roles change depending on the bounds or objectives. Every individual holon has three important characteristics: (i) It controls the lower level order of 
holons that comprise it. (ii) It is controlled or affected by those on a higher level than it. (iii) It is a complete system that could be investigated on its own [24,25] (Figure 1).

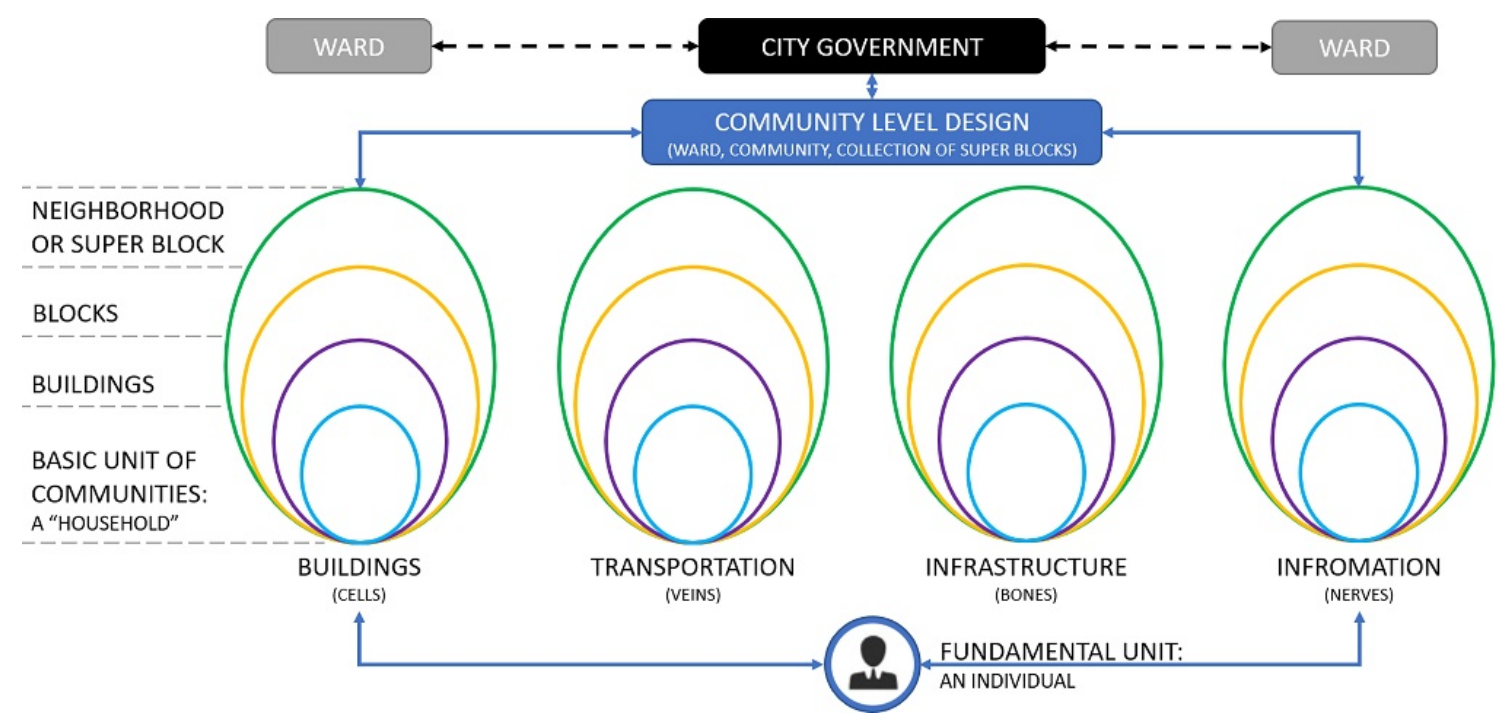

Figure 1. Holarchy of urban systems from the core holon, individuals and nature, to macro systems. Each smart community is then comprised of smaller interlocking sub-holon systems like buildings, transportation, infrastructure, and information.

Studying these complex system relationships in isolation would discount, or ignore, the ripple effect that a change in one system can have on another. This added layer exponentially increases the complexity, uncertainty, and difficulty in properly evaluating decisions of the models. However, the end results are more complete, justifiable, and grounded in the context for which the plans are developed. While the system components and stratification of its structure is important in providing understanding and affecting changes, the primary focus of these breakdowns are to use them for facilitating the creation of smart communities. These systems ultimately exist to serve the needs of humanity in the built environment and should aim to foster stronger connections between people, the built environment, and the natural world.

\section{A Conceptual Framework of Urban Systems Design (USD) Process}

The urban systems design is a proposition to address the above system complexity problems. A conceptual framework of its processes is discussed here that is aimed to address challenges in a systematic, humanistic, and cohesive manner. It is a model for planners, system designers, stakeholders, and communities to handle processes of planning complex urban systems and support decisions. The framework is divided into its three core elements: Contextualization, Evaluation, and Change and Iterative Continual Design. (Figure 2). 


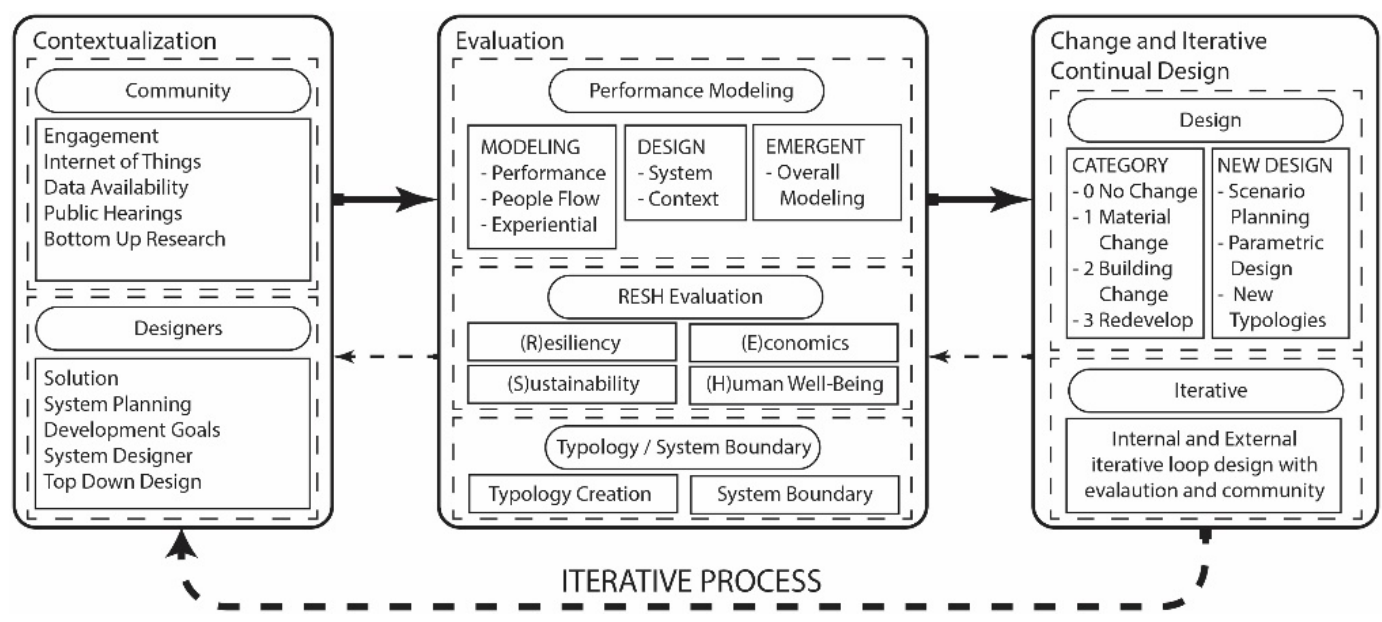

Figure 2. A conceptual framework of urban system design processes: Contextualization, Evaluation, and Change and Iterative Continual Design.

Urban systems design integrates urban design and systems science. It engages emergent information and communication technologies to address questions such as how cities function, or what properties emerge from interactive processes of urban systems. Big data, analytic techniques, and new planning methods are needed. "Urban systems design is an interventional approach regarding how future cities should be invented, and yet should be grounded in understanding the extent urban system of systems. Emergent properties of urban complex systems are to be derived to inform urban design [26]."

USD as a process model is divided into three core phases: Contextualization, Evaluation, and Change and Iterative Continual Design. Contextualization constructs the current dataset and conditions, combining the bottom-up processes from community engagement with the top-down approach from governmental policies and performance goals of the overall system. Evaluation employs a set of evaluative tools to judge the current conditions-tools which are then used in an iterative testing loop for all future designs. Change and Iterative Continual Design steps through the design and community engagement processes in selecting final designs and iterating through potential outcomes. Underpinning these three phases are four components that are essential to the USD model: Abstraction, Modeling, Evaluation, and Design. Abstraction is a necessary component of complex evaluation in which simplifying and categorizing information occurs. Examples such as buildings are categorized to various typologies. Modeling employs the tools, methods, and applications required to run metric-based evaluation for deriving emergent properties. Evaluation takes place once modeling has been conducted, comparing disparate models and information. An evaluation of USD can be accomplished through four pillars: (R)esliency, (E)conomy, (S)ustainability, and (H)uman Well-Being. Defining System Boundaries within spatial and temporal scale is a key to urban systems design, which refers to the area of interest (focus of the study), and how issues and problems are determined. Each of these individual components are expounded upon in this section.

\subsection{Abstraction}

Abstraction, in the USD framework, refers to two principal methods: scale-based and typology-based. Scale-based abstraction examines the metrics and granularity of the areas of the study: a single household, a neighborhood, an urban district, or a larger region. When moving through them, each of these different scales have differing resolutions and important characteristics that are essential to condense or expand upon. Modeling often relies on using these different scales in different manners. Transportation modeling tends to be large in scale, while the models are normally constructed from household- and block-level data. Urban building energy modeling examines building energy performance that relies on urban form, building design, systems, occupants and local climate data. Overall system integration transcends and connects each element together in a unified evaluation 
for a given scale and boundary (Figure 3). We define this stratification based on the qualities of holons arranged hierarchically into a set grouping of categories: Individual Agents (fundamental), Households (base unit of analysis), Buildings (extra small), Blocks (small), Districts/Superblocks (medium), Neighborhoods (large), Communities (extra-large), and cities.

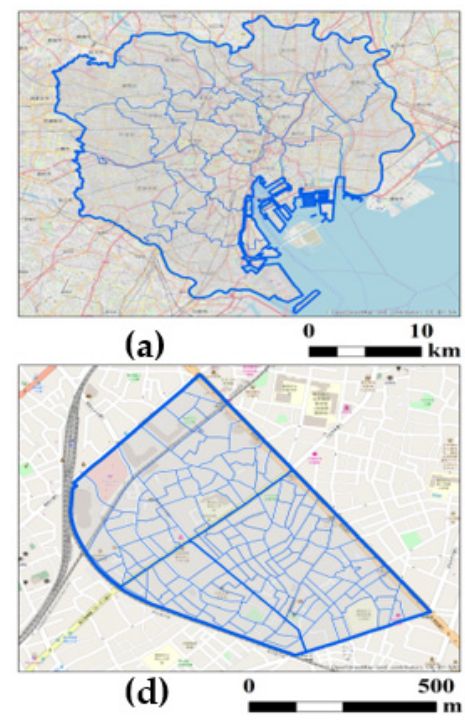

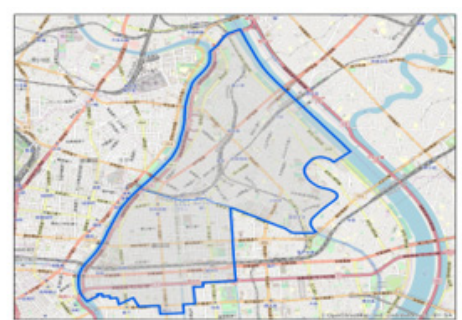

(b)

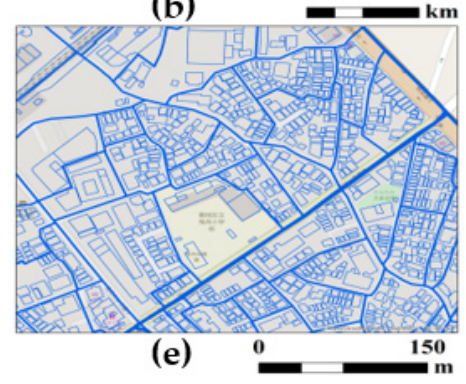

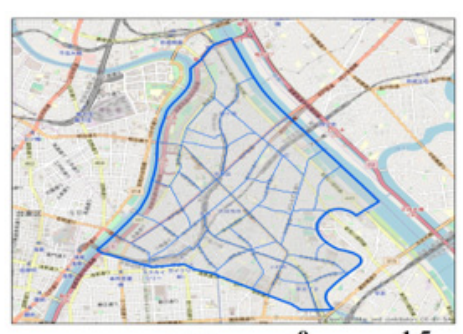

(c)

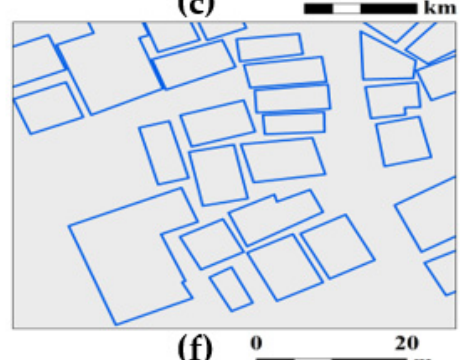

(f)

Figure 3. Various scales of abstraction in the urban environment, the central city of Tokyo (a); Communities, Sumida Ward (b) and North Sumida (c); Neighborhood, Kyojima (d); Blocks (e); and Buildings (f).

Typologies are important for contextualized and statistical abstraction, especially in examining large areas where individualized discrete data is inadequate, problematic, or does not exist. The basic elements of typologies are within one of the following categories: Form, Context, Use, and Structure (FoCUS). Each of these categories carries a different set of criteria that will make it a good or bad tool for categorization when studying a specific problem. Form, sometimes referred to as urban form, is the physical shape and other physical characteristics of a built environment. The Context refers to information needed to understand where and why it exists or what is affecting it. This ranges from the surrounding buildings, zoning, or transit lines to more macro-scale environments like rivers, forests, and mountains. Context can be used to determine the proximity of the location to amenities, such as how close the food store (food desert) is, or spacing in-between buildings that affects daylighting and urban ventilation. Use, or function, is a common element used in modeling, as almost all transportation and energy modeling requires this to run models. Structure refers to its internal physical components. Structural elements include mechanical systems, window types, and age of the building.

Abstractions are undertaken through manual coding and can be aided by computing tools. To create these categorizations when a study is conducted, an individualized contextual analysis based on methodological steps is required. Ideally, this process in the future could rely on community-based machine learning and edge computing to more accurately represent the stochastic and dynamic relationships that exist in cities. In-depth abstractions can be developed by classifying buildings using visual analysis tools like those employed by street views and classification software, using land-use data, and utilizing Building Information Modeling (BIM) to record data of building geometry, materials, use patterns, time scheduling and cost... etc.

\subsection{Modeling}

In current practice, there are many issues in the way modeling is completed and how these models integrate and interact with planning and design principles. Different scales of modeling are completed in different ways for tackling different problems, whether it is for a private development, 
for a community plan, for an extended arterial corridor study, or for an interstate/freeway corridor study. Analyses are often completed in a silo for site-specific developments. Modelers tend to react to simple conditions instead of recommending solutions for complex system problems and their future changes. The USD framework seeks to close the gap between designers and modelers, as these tasks are to be jointly handled by them. It's a process to utilize a looping method of redesign and verification [27].

The USD framework relies on blending the analytics and design. It is important that value, information, and data can be compared across models and methods to meet the accepted criteria using the USD. The performance modeling criteria are divided into three modeling methods (Performance; People Flow; Experiential), two design integrated approaches ("Bottom-Up" Context; "Top-Down" System), and one overarching model (Figure 4).

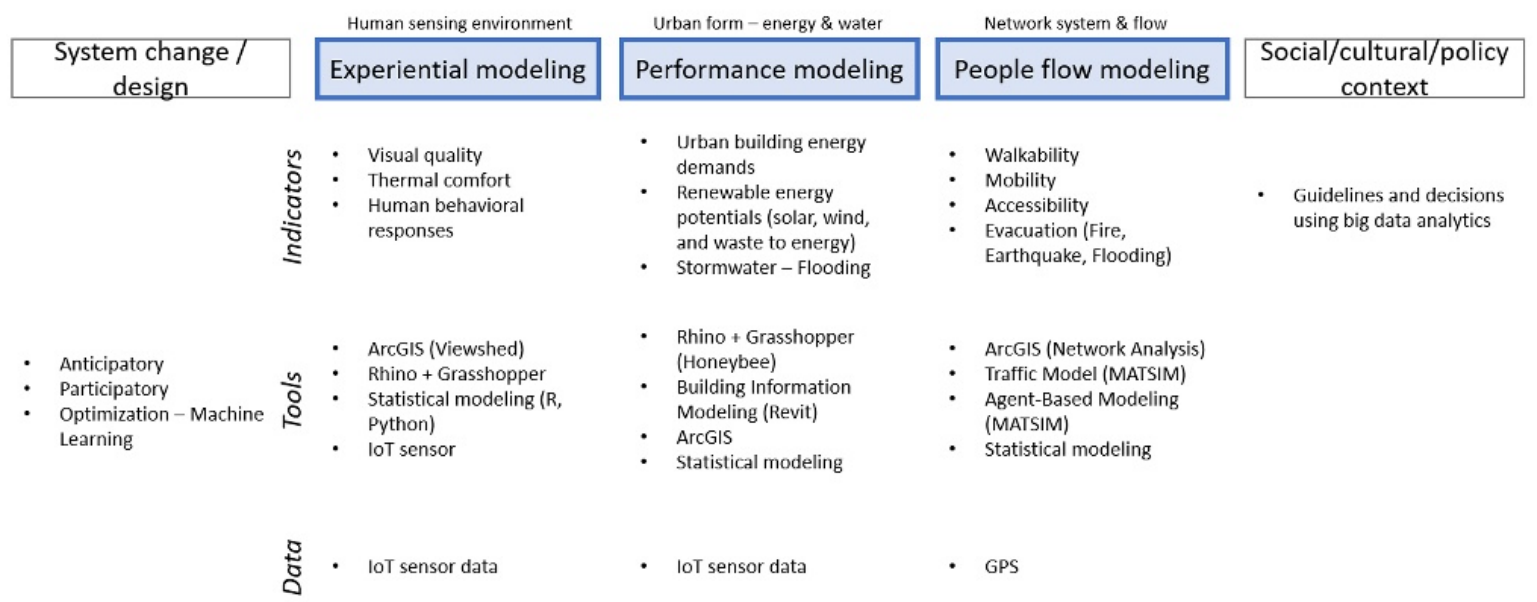

Figure 4. An overall framework of urban systems design including three modeling methods and their objectives, indicators (qualitative and quantitative), tools used for modeling, and their relevant data inputs.

\subsubsection{Performance Modeling}

The performance modeling method is goal-driven and objective-oriented. In these models, the data can range from hard to soft. Hard data is defined as quantitative data in the form of numbers or graphs. Hard data describes the types of data that are measured, traced, validated and generated from devices and applications, such as phones, computers, sensors, smart meters, traffic monitoring systems, call detail records, bank transaction records, among others [28]. Soft data is usually derived from qualitative measures, and sometimes immeasurable. Quantitative models include energy use modeling, carbon emissions, energy supply, food supply, logistics chains, etc. For modeling buildings and block-scale built environment, tools like Rhino, Grasshopper, EnergyPlus, and BIM are useful. For modeling network, macroscopic, mesoscopic, and microscopic simulation tools are used. All modeling is encompassed by statistical modeling. The desired outputs of measures-of-effectiveness (MOEs) are based on the chosen goals of the analyses, and the outputs are then compared to the objectives of the analyses. These results are weighted against the other modeling methods, and it is then decided whether the process must loop-back into model adjustment and redesign.

\subsubsection{People-Flow Modeling}

People-flow modeling deals with the movement of people throughout urban environment, which consists of hard and mixed data types. As mentioned, the models can be macroscopic, mesoscopic, or microscopic in nature, which is usually decided upon data availability. Specifically, the people-flow modeling investigates the effects of the movements and flows at the network-level and most often, 
the transportation/traffic with or without the use of a vehicle in the built environment. The main aspect of this modeling is to expand and change the focus from transportation-only foci (vehicle-based modeling) to people/agent-based modeling that can investigate how walking, autonomous vehicles $(\mathrm{AVs})$, and other new system designs affect the city. The additional information that is now available with big data creates the possibility for agent-based simulation which includes network schedules and patterns based on origin-destination data points. It is important to note that these data and modeling methods can also reach other metrics and data included in the performance and experiential modeling methods. This overlapping modeling methods can enrich our understanding of people flow patterns, urban forms and their interactions that generate human experiences. An example is the outdoor human comfort modeling, which is a hard metric that also impacts the modeling and data of people flow.

\subsubsection{Experiential Modeling}

Experiential modeling refers to modeling methods, tools, and metrics that can quantify and qualify the human or sensory experiences that impact or originate from the city or object of study. Often data and information studied by these models include soft/mixed data types with the use of harder (quantitative) information being a proxy for actual human experiences. Examples of this would be thermal comfort in outdoor spaces and the visual quality of street views. Thermal comfort is highly dependent on the individual locations and movements based on a number of factors that can be studied and combined as a proxy (i.e., radiation, temperature, wind and humidity, etc.). One way of assessing human visual experience in urban environment is through public outreach, surveys, and field studies to determine what qualities that users find appealing. The data can then be used to train algorithms to potentially approximate users' preference. However, this should be applied with care given the ease of miss training or errors in machine learning. Together with performance and people-flow modeling, experiential modeling reaches the human-scale and human-effect of the current and future decisions made for and within the built environment.

\subsubsection{Design}

Design, or system change, focuses less on the immediate use of analytical modeling tools and instead seeks to blend the modeling and planning methods into a unified and coherent new system through a synthesis approach. Where the analytical methods are to provide the basic metrics for evaluation, design aims to understanding contexts, and focuses on social interactions, stakeholders engagement, and creative thinking through inductive reasoning.

Design as a change model tends to reply on a top-down approach. Designers and planners identify problems, state their intent, find potential opportunities and use anticipation to generate concepts and solutions to these issues they have identified. Design often relies on a priori thought and deductive reasoning that can be judged and needs to work in tandem with contexts. An example is the push for mass adoption of autonomous vehicles into communities prior to understanding the potential effects. Another example is the introduction of photovoltaic (solar) panels that must first be corrected and gauged in context. It is also managed in dialogue flows between modeling and design processes. Through iterations, professionals can evaluate outcomes based on the goals and objectives through community engagement to make final design decisions.

From the three modeling methods, performance, people flow, experiential, and their integration in design, an overall framework of urban systems design would emerge. The framework offers a process to address how urban system changes would arise from complex and non-linear system interactions. The selection of modeling tools and techniques is to be contextualized, and to a certain degree, determined based on issues defined by the system boundary. Evaluation of the modeling results will inform iterative and continual design processes for moving urban systems change. 


\subsection{Resilience, Economic Success, Sustainability, and Human Well-Being (RESH) Evaluation}

Resilience, Economic Success, Sustainability, and Human Well-Being (RESH) are the four pillars of this framework - used as the key evaluation and validation criteria. Each of the four pillars of RESH act as a three-dimensional trade-off matrix for evaluating current and projected future conditions (Figure 5), but by themselves can be nebulous in their definition depending on the context, field of study, and application. Resilience examines the ability of a system to resist or recover from stress-indicators of which can be based on the assessment of an area's vulnerability to flooding, fire risks, or earthquakes. Economic success, or further aggregated to mean individual and community prosperity, is built upon the needs of individuals and businesses in cities. Given our current social structures-economic success can be measured by worker-to-housing balance, the transportation network, or economic growth. Sustainability can be defined in many ways, but for USD specifically, it is used to explore environmental sustainability - via solar potential, energy supply, energy demand, or food and waste cycles. Human Well-Being is the measure which contains all social and tactile systems that are fundamental to how humans interact, live, and use the city-metrics like heat-island effect, walkability, thermal comfort, or heat risk assessments are all of use. With these definitions and methods, RESH can be utilized by evaluating the quantitative indicators from modeling, their trade-offs and how they are operated and managed by considering inputs and outputs within a particular urban context. While quantitative metrics are needed, qualitative metrics are crucial for a better understanding of how humans, nature, and urban spaces work together as interdependent systems. To further aggregate the RESH concept into evaluation and validation criteria, it was necessary to consider existing literature that looks deeply at each of the pillars.

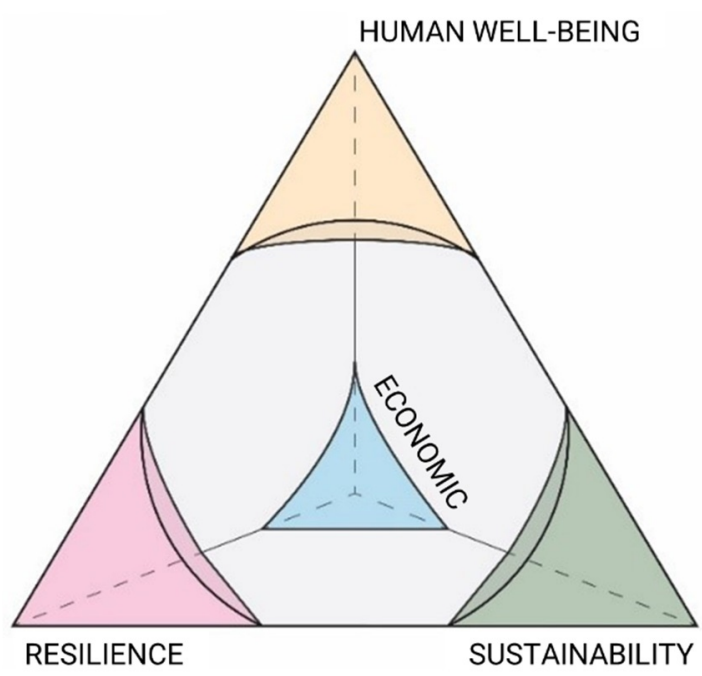

Figure 5. Three-dimensional trade-off matrix between resilience, economics, sustainability, and human well-being (RESH) evaluation metrics (created based upon [29]).

\subsubsection{Resilience}

The concept of resilience in the urban context is defined as the ability for a particular geographic area to return or recover to its original status after experiencing shocks either physically, socially, or psychologically [30]. "Shocks" (or stresses) can be caused naturally or intentionally, and it may cause urban systems to fail [31]. "Recovery" from the damages can include restoration to the original positions or an update to develop or redevelop systems [31]. Since potential hazards such as hurricanes, earthquakes, heat waves, etc., can be increased more by climate change [32] and these types of disaster risks influence the urban systems' failure [33], resilience becomes significant for human settlements [34].

To summarize, this study categorizes the constituent elements of urban systems into governance, infrastructure and the built environment, socioeconomics, and the natural 
environment (Figure 6). The elements and sub-elements are defined by cross-validating different literature $[10,27,28,30-33,35-39]$.

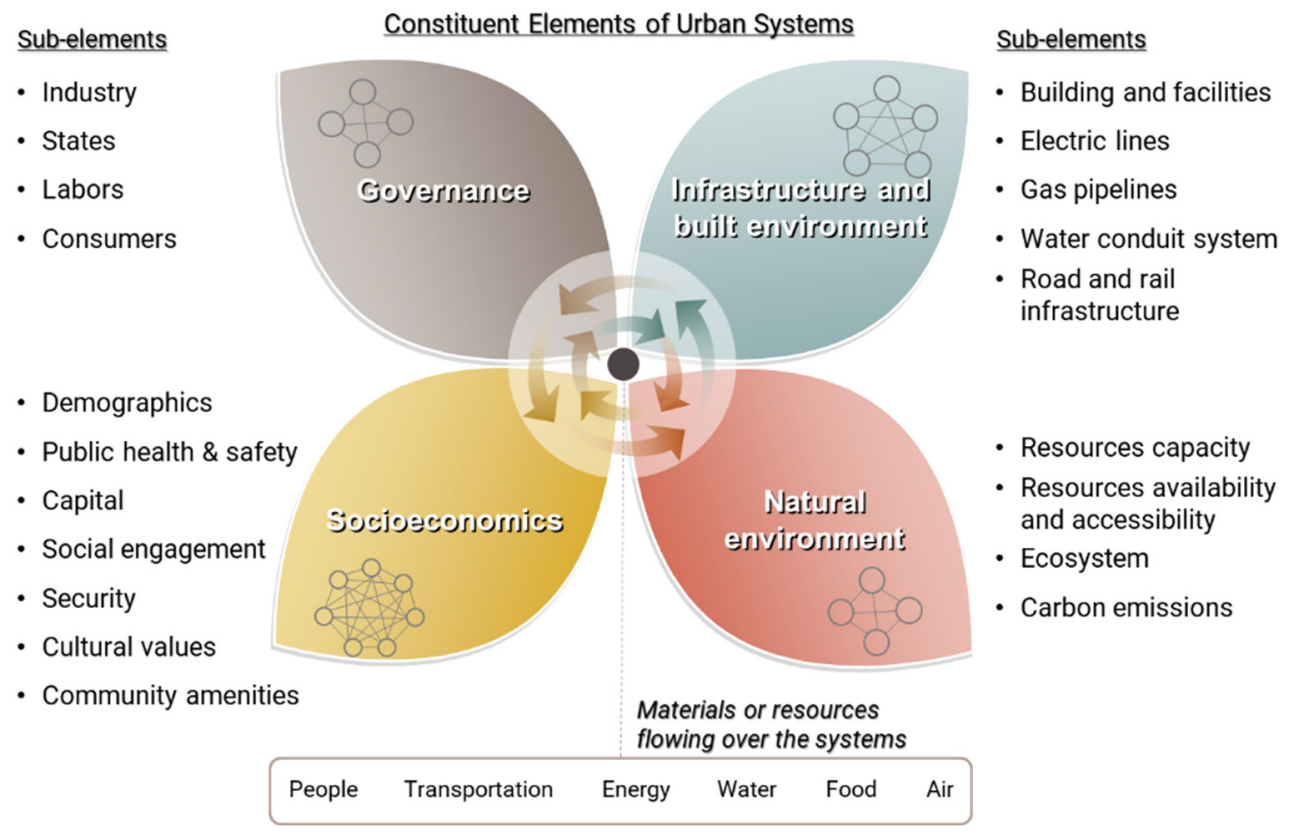

Figure 6. Stocks and flows constituting the urban systems.

The evaluation criteria of urban resilience should be applicable for any given types of stresses, systems, and recovery. By considering resilient phases and given conditions, this study develops the framework for evaluating the urban resilience [10,34] (Figure 7).

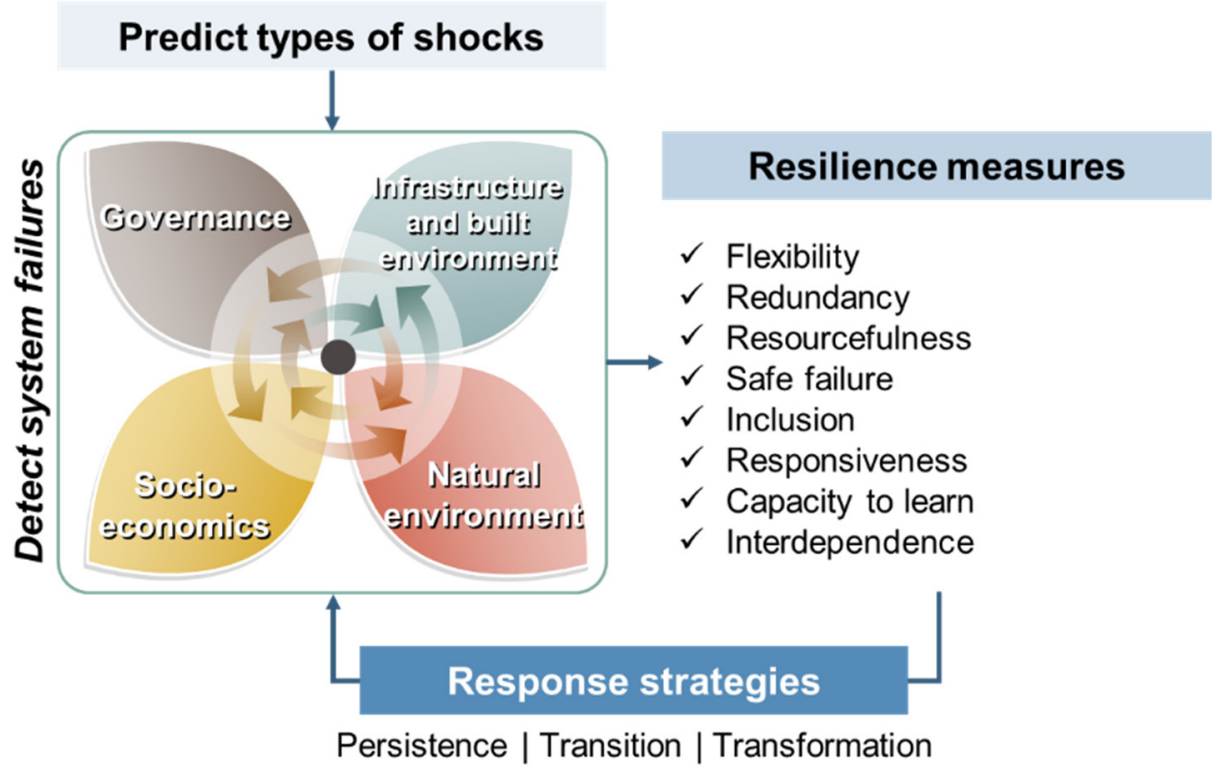

Figure 7. Evaluation framework for urban resilience.

\subsubsection{Economics}

An urban economy can be defined as an economy that sustainably builds market structures and business environments into those that can acquire economic growth, prosperity, and competitiveness [40]. The urban economy can be evaluated with inputs (cost) and outputs (benefits) of urban systems [41], but must also include considerations of equity. Economic growth can 
be driven by human capital, physical capital (i.e., infrastructure and built environment), innovation (in public and private sectors), and spatial conditions [42]. Hammer et al. (2011) identified indicators for economic growth as job creation, demands of products or services, and urban attractiveness for investment [42]. The outcomes of urban economies are defined by job creation (employment), demands of products or services, supply of products or services, shared prosperity, and investment opportunity. These outcomes can be designated as the evaluation criteria for the urban economy in the proposed framework (Figure 8).

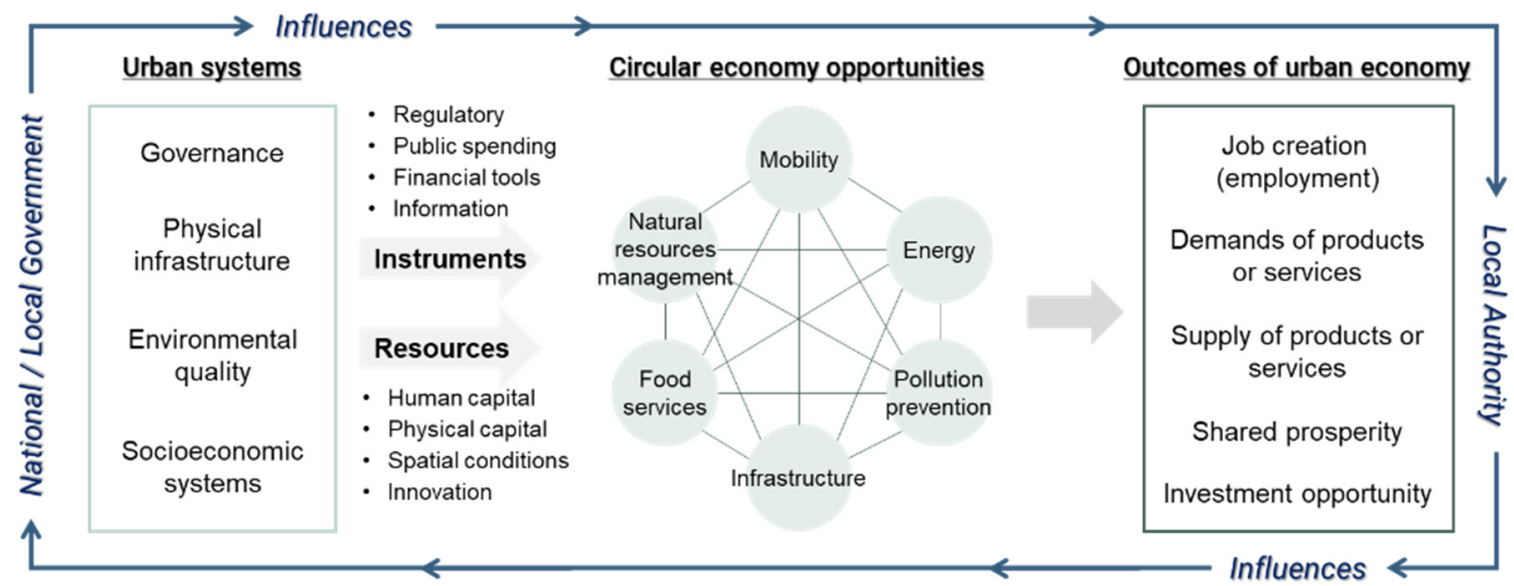

Figure 8. Evaluation framework for urban economy growth (Adapted from [42]).

\subsubsection{Sustainability}

Sustainable systems can be defined as the systems' processes and conditions being maintained forever without decreasing value or performance [43]. Sustainability has often encompassed the environment, economy, and society [44]. Urban sustainability can be achieved by actively integrating or collaborating between subsystems to minimize harmful consequences on the ecosystem [45]. To integrate the diverse subsystems, the urban sustainability framework requires four stages: (1) diagnosis, (2) vision and priorities for actions, (3) financing the plan, and (4) monitoring framework [40]. In this respect, urban sustainability can be evaluated by whether the inflows and outflows over urban systems deviate from manageable ranges, and within this framework should have a focus towards environmental sustainability within the urban context (Figure 9).
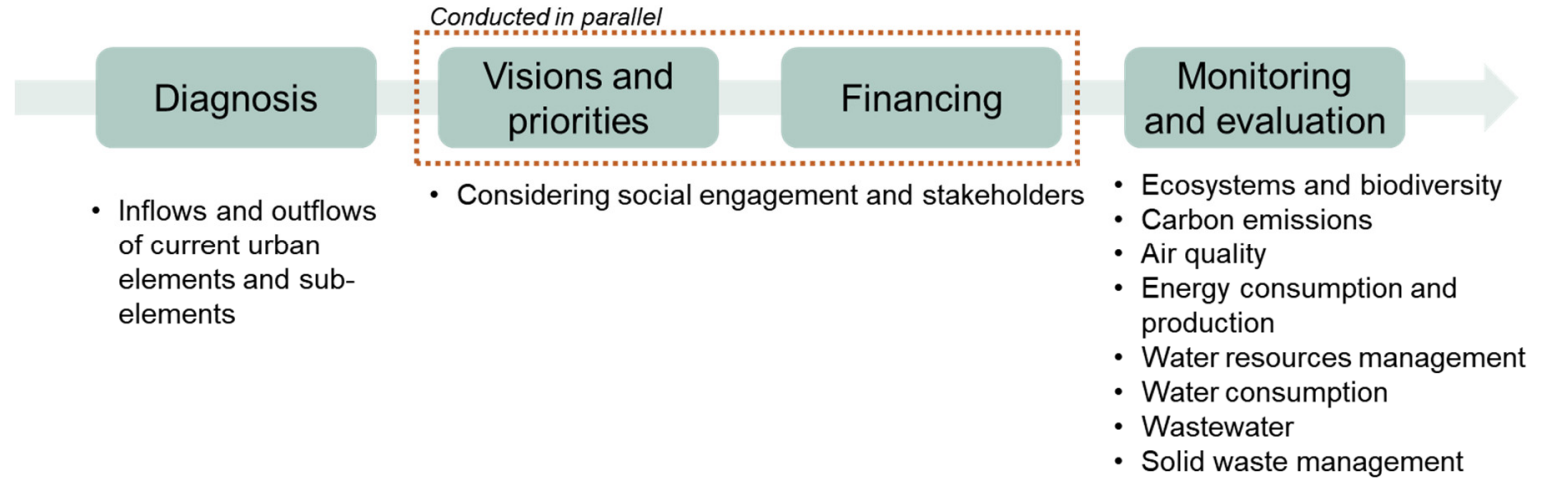

Figure 9. Evaluation framework for the urban sustainability (adapted from [40]).

\subsubsection{Human Well-Being}

Human well-being is the key purpose of urban systems [33]. Da Silva et al. (2012) identified the components of well-being as the basic needs for survival, security, health, good social relations and esteem, and freedom of choice and action [33]. Arup (2014) defined human health and well-being as 
consisting of minimal human vulnerability, livelihoods and employment, and safeguards to human life and health [46]. Human well-being requires the functionality of urban systems with a stable or increasing experience for people in diverse living conditions [47]. Socioeconomics in urban systems, including materials and resources flowing through the urban systems, become important attributes to measure human well-being. Other urban systems (governance, infrastructure, and natural environment) can support the formation of the evaluation criteria. The evaluation criteria framework for human well-being is presented in Figure 10.

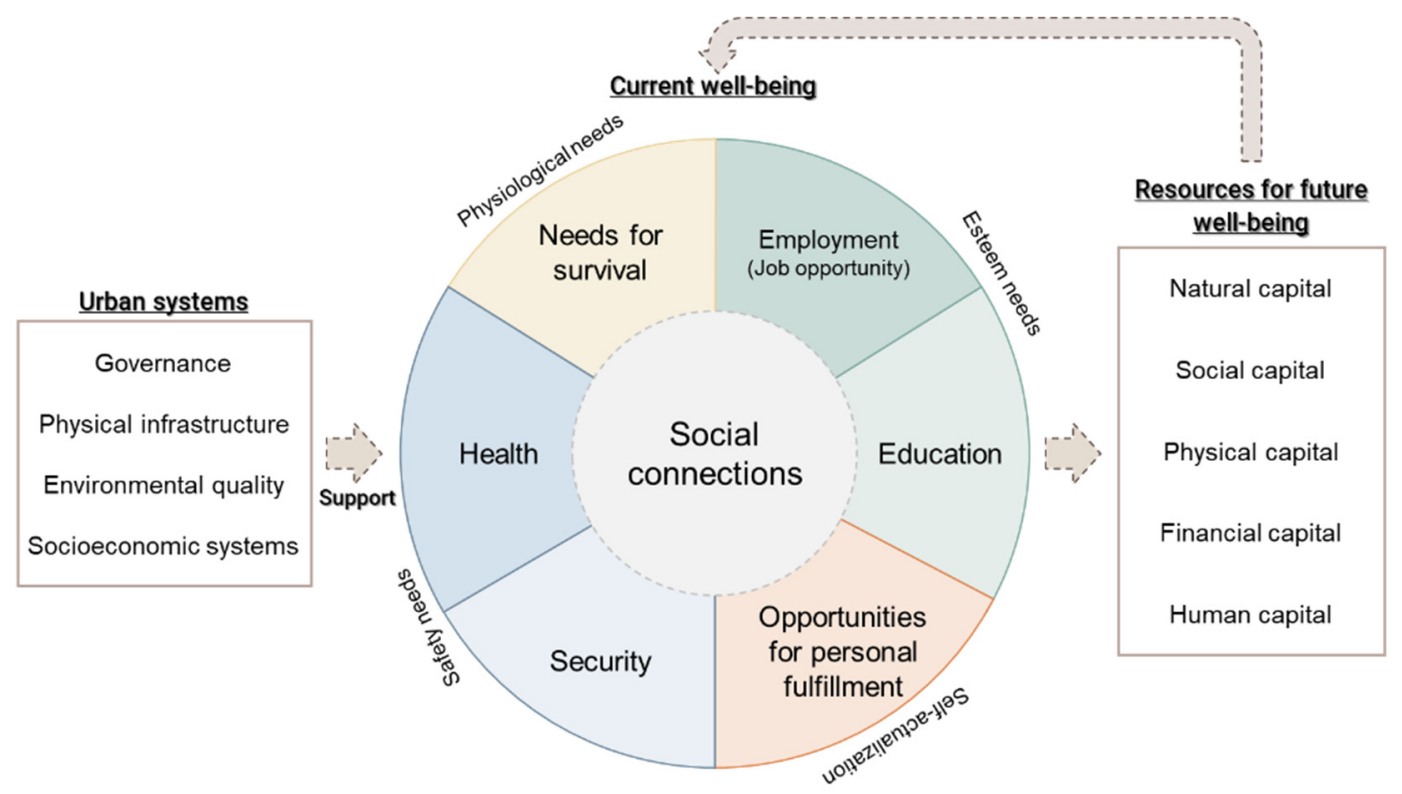

Figure 10. Framework for measuring human well-being and progress (adapted from [47]).

\subsection{System Boundaries}

The creation of system boundaries, or study boundaries, is the first step toward initiating the performance modeling for a planning and design study utilizing the urban systems design conceptual framework. In studying problems and applying metrics, boundaries serve the purpose of focusing and providing restrictions to what otherwise can be edgeless systems. For the initial phases of the study, the system boundaries can be categorized into five types: Study, Infrastructure, Administrative, Community/Social, and Procedural. The Study boundary focuses on the area that is restrained by the questions that a study seeks to address. The Infrastructure boundary uses infrastructure or nature to form the boundaries of an area. The Administrative boundary uses the bounds set by administrative agencies to segment space. The Community/Social boundary uses how communities and social areas self-identify to inform the conditions of the study. The Procedural boundary automates the above methods to generate more localized conditions of boundaries.

The Procedural boundary is the most powerful boundary among the categories because it combines the other methods under one umbrella. An example of the development of the Procedural boundary is to choose the three key destinations, and the radii vector between or around them, that are considered most important in a community to create the centroid of a study area at the neighborhood, or microsimulation, scale. In the Japanese urban context, it is believed that the radii between the local market (or Kira-Kira), the local shrine or community space, and the nearest transit station, along with the level of human comfort experienced along these radii, create the routine walkshed in a neighborhood. This routine walkshed could make sense as the study boundary for a small-area study. The measures in this boundary development create an additional connection to RESH and act as the interaction interface between design spaces. 
A potential addition to the Procedural boundary development utilizes a more community-centric approach in that it would relate directly to a set of questions to be asked of the residents of a neighborhood. The home location and the points of interest of the individuals would be mapped. The walkshed would then be developed from iterations of the radii distances between home and points of interest found in the individual responses.

\section{USD Phases}

A conceptual framework of urban systems design is segmented into three core phases: Contextualization, Evaluation, and Change and Iterative Continual Design (Figure 11).

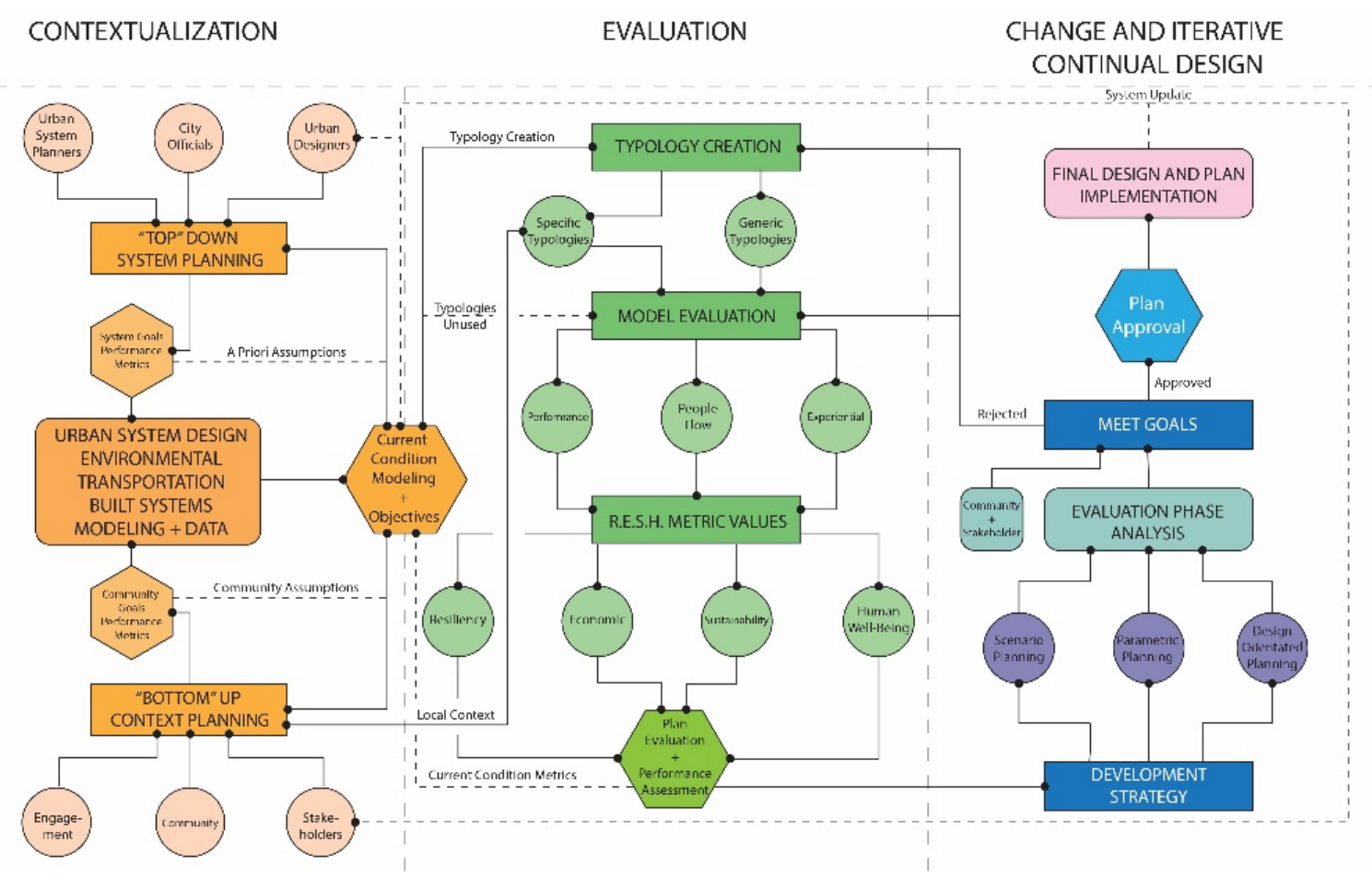

Figure 11. Urban system design system diagram and programmatic steps in its implantation process.

Contextualization develops the physical (modeled), social (engagement), and evaluative (objective) properties and metrics of the area of interest, defining the limits and scope of the project. Evaluation uses modeling tools to generate metrics based on the RESH categories to establish how trade-offs, between mutually exclusive choices, are weighed for current and future scenarios. Typologies are created and evaluated in this phase. Change and Iterative Continual Design incorporates RESH metrics, human design choices, parametric modeling, and the objective identifiers (noted in phase 1) to create alternatives and to constantly monitor and loop through the USD framework once applied to a space. If the alternatives do not meet the goals that were originally set-out by the community, the process loops back to the existing conditions (Contextualization) and typology creation (Evaluation) - an essential element of the effort of this framework to achieve community goals and the goals within the RESH evaluation.

\section{Conclusions}

We present a conceptual framework of urban systems design—driven by the goals of Resilience, Economic Success, Sustainability, and Human Well-Being-which relies on joint modeling and mixed evaluations of current conditions to address new challenges of urban design and planning in the context of smart cities movement. In current planning practice, we often see that a single or several performance criteria and indicators represent the RESH metrics. However, the proposed USD conceptual framework 
shows the possibility of combining the performance evaluation and the engagement of a community while considering impacts of design for changing urban systems. The implications of this framework for planning and design are significant because it brings together the often-clashing theories of rational planning and the social and communicative approaches under one analysis umbrella which considers new and future technologies and methods while utilizing big data sources. The methodology is enhanced by the understanding of the previous failures of the top-down system-driven methods of planning from 1950s that is to be refined in the new context of emerging technologies and smart cities. These important aspects of the framework allow those in the profession to better understand the desires and needs of the average citizen, in relation to mutually exclusive objectives, potentially in a greater way than current public involvement practices can achieve. This is all made possible by new data, novel evaluation and design methods that should be used to better manage our current urban systems, to develop a feedback loop in design using modeling and analysis that enhances design towards community goals, and to influence how urban systems could be changed in the future. Rather than solidifying a strict implementation guideline of RESH criteria, we hope that users of this framework can broaden their opportunities to use new planning methods based on these four pillars. New technologies are to be driven by community goals that are context-specific and equity-focused. Interrelationships among the four pillars can be further investigated for a more iterative urban planning practice and as a governing principle based on the USD concept. Future study will need to explore the interdependencies among the four pillars to support optimization of the performance of urban scenarios, while considering trade-offs and other examples of planning support systems as further justification for the USD approach. The question of how we should apply USD framework to actual urban contexts remains challenging. Practices and issues should continue to be investigated with local stakeholders in other locations to strengthen and test the framework.

Author Contributions: Concept development, M.B.T., R.B.B., S.C., T.Y., Y.Y. and P.P.J.Y.; data curation, T.Y.; writing—draft preparation, M.B.T., R.B.B., S.C., and T.Y.; writing-review and editing, M.B.T., R.B.B., S.C., Y.Y. and P.P.J.Y.; visualization, M.B.T. and S.C.; projects supervised by Y.Y. and P.P.J.Y.

Funding: This research was funded by National Institute for Environmental Studies and Global Carbon Project.

Acknowledgments: Our team would like to take this opportunity to thank the administrative staff with the Global Carbon Project at the National Institute for Environmental Studies. Without their hard work and efforts, our team would not have had the opportunity to work together at the Institute in Tsukuba, Japan. Additionally, we must acknowledge the hard work of the Spring 2016, 2017, and 2018 International Urban Design Studios from School of City and Regional Planning and School of Architecture of the Georgia Institute of Technology, who utilized urban systems design methods in their studio which laid the groundwork. We have special thanks to Akito Murayama from the Department of Urban Engineering of the University of Tokyo for his advice on Tokyo urban planning. Finally, we acknowledge Sycamore Consulting in Decatur, Georgia of the U.S., who laid the groundwork for discussions of community engagement methods that were utilized.

Conflicts of Interest: The authors declare no conflict of interest.

\section{References}

1. Taylor, N. Urban Planning Theory since 1945; SAGE Publications Ltd.: London, UK, 1998.

2. Davidoff, P. Advocacy and pluralism in planning. J. Am. Inst. Plan. 1965, 31, 331-338. [CrossRef]

3. Healey, P. Collaborative Planning: Shaping Places in Fragmented Societies; Macmillan International Higher Education: London, UK, 1998. [CrossRef]

4. World Commission on Environment and Development. Our Common Future-Report of the World Commission on Environment and Development (The Brundtland Report). Med. Confl. Surviv. 1987. [CrossRef]

5. Morris, A.E.J. History of Urban form Before the Industrial Revolution, 3rd ed.; Routledge: London, UK, 2013.

6. Howard, E. Garden Cities of To-morrow; Routledge: London, UK, 2013. [CrossRef]

7. Parsons, K.C. Collaborative genius: The regional planning association of America. J. Am. Plan. Assoc. 1994, 60, 462-482. [CrossRef]

8. Jacob, J. The Death and Life of Great American Cities; Random House: New York, NY, USA, 1961. 
9. Eraydin, A. "Resilience Think" For Planning. In Resilience Thinking in Urban Planning; Eraydin, A., Tasan-Kok, T., Eds.; Springer: Dordrecht, The Netherlands, 2013; pp. 17-37.

10. Meerow, S.; Newell, J.P.; Stults, M. Defining urban resilience: A review. Landsc. Urban Plan. 2016, 147, 38-49. [CrossRef]

11. ISO 9241-210:2010. Ergonomics of human-system interaction-Part 210: Human-centred design for interactive systems (ISO 9241-210:2010). Int. Stand. Organ. 2010. [CrossRef]

12. Sanoff, H. Origins of Community Design. PN Plan. Netw. 2005, 166, 14-17.

13. Albino, V.; Berardi, U.; Dangelico, R.M. Smart Cities: Definitions, Dimensions, Performance, and Initiatives. J. Urban Technol. 2015, 22, 3-21. [CrossRef]

14. Friedmann, J. Why Do Planning Theory? Plan. Theory 2003, 2, 7-10. [CrossRef]

15. Portugali, J. Complexity Theories of Cities: Achievements, Criticism and Potentials. In Complexity Theories of Cities Have Come of Age; Tan, E., Portugali, J., Eds.; Springer: Berlin/Heidelberg, Germany, 2012; pp. 47-62. [CrossRef]

16. Scott, A.J.; Storper, M. The nature of cities: The scope and limits of urban theory. Int. J. Urban Reg. Res. 2015, 39, 1-15. [CrossRef]

17. Batty, M.; Axhausen, K.W.; Giannotti, F.; Pozdnoukhov, A.; Bazzani, A.; Wachowicz, M. Smart cities of the future. Eur. Phys. J. Spec. Top. 2012, 214, 481-518. [CrossRef]

18. Batty, M. The size, scale, and shape of cities. Science 2008, 319, 769-771. [CrossRef] [PubMed]

19. Freudendal-Pedersen, M.; Kesselring, S.; Servou, E. What is smart for the future city? Mobilities and automation. Sustainability 2019, 11, 221. [CrossRef]

20. Bamwesigye, D.; Hlavackova, P. Analysis of Sustainable Transport for Smart Cities. Sustainability 2019, 11, 2140. [CrossRef]

21. Fistola, R.; Gargiulo, C.; Battarra, R.; La Rocca, R.A. Sustainability of urban functions: Dealing with tourism activity. Sustainability 2019, 11, 1071. [CrossRef]

22. Al-Thani, S.K.; Skelhorn, C.P.; Amato, A.; Koc, M.; Al-Ghamdi, S.G. Smart technology impact on neighborhood form for a sustainable Doha. Sustainability 2018, 10, 4764. [CrossRef]

23. Ladyman, J.; Lambert, J.; Wiesner, K. What is a complex system? Eur. J. Philos. Sci. 2013, 3, 33-67. [CrossRef]

24. Yang, P.P.-J.; Wiedenback, A.; Tobey, M.; Wu, Y.; Quan, S.J.; Chauhan, Y. Material Based Urban Modeling: An Approach to Integrate Smart Materials in a Near-Zero Community Design. Energy Procedia 2017, 105, 3765-3771. [CrossRef]

25. Koestler, A. Beyond atomism and holism—-the concept of the holon. Rules Game Interdiscip. Transdiscipl. Anal. Model. Sch. Thought 2013. [CrossRef]

26. Yang, P.P.; Yamagata, Y. Urban Systems Design: From "science for design" to "design in science". Environ. Plan. B Urban Anal. City Sci. 2019, 46, 1381-1386. [CrossRef]

27. Binder, R.B.; Lancaster, Z.; Tobey, M.; Jittrapirom, P.; Yamagata, Y. Transport modeling with a purpose: How urban systems design can bridge the gaps between modeling, planning, and design. WIT Trans. Built. Environ. 2019, 186, 85-96.

28. Objectivity. Hard Data vs. Soft Data. Industrial IoT; Objectivity Inc.: San Jose, CA, USA, 2015.

29. Tobey, M.B.; Binder, R.B.; Yoshida, T.; Yamagata, Y. Urban Systems Design Case Study: Tokyo's Sumida Ward. Smart Cities 2019, 2, 453-470. [CrossRef]

30. Barata-Salgueiro, T.; Erkip, F. Retail planning and urban resilience-An introduction to the special issue. Cities 2014, 36, 107-111. [CrossRef]

31. Maruyama, H. Taxonomy and General Strategies for Resilience. In Urban Resilience; Yamagata, Y., Maruyama, H., Eds.; Springer: Cham, Germany, 2016; pp. 3-21. [CrossRef]

32. Ackerman, F.; Stanton, E.A.; Hope, C.; Alberth, S.; Fisher, J.; Biewald, B. The Cost of Climate Change: What We'll Pay if Global Warming Continues Unchecked; Natural Resources Defense Council: New York, NY, USA, 2007.

33. Da Silva, J.; Kernaghan, S.; Luque, A. A systems approach to meeting the challenges of urban climate change. Int. J. Urban Sustain. Dev. 2012, 4, 125-145. [CrossRef]

34. Sharifi, A.; Yamagata, Y. Resilient Urban Planning: Major Principles and Criteria. Energy Procedia 2014, 61, 1491-1495. [CrossRef]

35. Derrible, S. Complexity in future cities: the rise of networked infrastructure. Int. J. Urban Sci. 2017, 21, 68-86. [CrossRef] 
36. Desouza, K.C.; Flanery, T.H. Designing, planning, and managing resilient cities: A conceptual framework. Cities 2013, 35, 89-99. [CrossRef]

37. Derrible, S. Urban infrastructure is not a tree: Integrating and decentralizing urban infrastructure systems. Environ. Plan. B Urban Anal. City Sci. 2017, 44, 553-569. [CrossRef]

38. Sharifi, A. A critical review of selected tools for assessing community resilience. Ecol. Indic. 2016, 69, 629-647. [CrossRef]

39. Collier, M.J.; Nedović-Budić, Z.; Aerts, J.; Connop, S.; Foley, D.; Foley, K. Transitioning to resilience and sustainability in urban communities. Cities 2013, 32, S21-S28. [CrossRef]

40. Global Platform for Sustainable Cities (GPSC). Urban Sustainability Framework. Available online: https: //www.thegpsc.org/usf (accessed on 30 August 2019).

41. Liang, X. Integrated Economic and Financial Analysis of China's Sponge City Program for Water-resilient Urban Development. Sustainability 2018, 10, 669. [CrossRef]

42. Hammer, S.; Kamal-Chaoui, L.; Robert, A.; Plouin, M. Cities and Green Growth: A Conceptual Framework; OECD: Paris, France, 2011. [CrossRef]

43. Alberti, M. Measuring urban sustainability. Environ. Impact. Assess. Rev. 1996, 16, 381-424. [CrossRef]

44. Huang, L.; Wu, J.; Yan, L. Defining and measuring urban sustainability: a review of indicators. Landsc. Ecol. 2015, 30, 1175-1193. [CrossRef]

45. Zhang, X.; Li, H. Urban resilience and urban sustainability: What we know and what do not know? Cities 2018, 72, 141-148. [CrossRef]

46. Arup and the Rockefeller Foundation. City Resilience Framework City Resilience Index; Arup and the Rockefeller Foundation: London, UK, 2014.

47. OECD. How's Life? 2017: Measuring Well-Being; OECD Publishing: Paris, France, 2017. [CrossRef]

(C) 2019 by the authors. Licensee MDPI, Basel, Switzerland. This article is an open access article distributed under the terms and conditions of the Creative Commons Attribution (CC BY) license (http://creativecommons.org/licenses/by/4.0/). 